\title{
Effect of Teacher Attitudes on Academic Performance of Pupils in Public Primary Schools in Hargeisa District
}

\author{
Gulled M. Yassin \\ School of Graduate Studies, University of Hargeisa, Somaliland
}

\begin{abstract}
Teacher attitude is a pertinent determinant that involves sincere sensitivity to the desire of students and the overall willingness to participate in classroom responsibility.This study delved into the effect of teacher attitudes on pupils' academic performance (AP) in public primary schools in Hargeisa, Somaliland, with the main purpose of enhancing quality of education in Somaliland. The study was fueled by the fact that Somaliland's educational standards had declined, which had been linked to teachers' attitudes. The rising number of Somaliland National Exams (SLNECB) exam failures reflected the decline in academic performance. Despite an increase in failure, as shown by Somaliland's national exam results, the effect of teacher attitudes on student performance had not examined. Employed cross-sectional research design, data was obtained using a questionnaire from a stratified random sample technique of teachers in Hargeisa public primary schools, and document analysis and was analyzed using ANOVA One Way. The study found out that teacher attitudes significantly affect on students' academic performance in Hargeisa district public primary schools.
\end{abstract}

Keywords: Academic performance, teacher attitudes, Somaliland National Exams, public primary schools

DOI: $10.7176 / \mathrm{JEP} / 12-15-08$

Publication date:May $31^{\text {st }} 2021$

\section{INTRODUCTION}

The determinants of the success of pupils have been the subject of ongoing debate among educators, academics and policy makers, and one of the most important factors is teacher attitudes (Ngina, 2013). In Somaliland, little study has been carried out on the effects of teacher attitudes on pupils ' academic success. Thomas and Znaniecki (1918) describe the attitude of the instructor as a process of individual consciousness that defines the individual's actual or potential behavior in the social environment.

According to Bogardus (1928), the attitude of teachers is a propensity to behave for or against something that becomes a positive or negative attribute in the school setting. Moreover, Wolfe (1923) described the attitude of the instructor as the form of feeling that the person exhibits upon the recurrence of a situation. Both of these meanings suggest that teacher attitudes are the creation of what individuals judge or have a positive or negative feeling about.

Teacher attitudes can be measured by the domains of affective component, behavioral component and cognitive component (L.Gregory\&Noto, 2017). In this study, teacher attitudes can be indicated from the ABC model of attitude measurement.

Teachers' attitudes have been linked to academic performance. For example, A research was used to discover how teacher attitudes influence student success. A total of 353 students from different departments of Istanbul Kultur University and Maltepe University were part of the study sample community. The students were asked to provide samples of the positive and negative attitudes of their primary school, middle school, high school and university teachers by giving a questionnaire and to explain how it affects learning by giving samples. The most significant results of the study showed that the positive attitudes of teachers had a positive impact on the academic performance of students.

More so, a study conducted by Sutton (2013) investigated the relationship between teacher attitudes and the academic performance of students. A survey was conducted resulting in 105 participants whom were all general education teachers within an elementary or middle school. After receiving questionnaires for this quantitative study, responses were analyzed using SPSS reports of descriptive statistics, ANOVA, and Pearson Correlations. The findings of this study suggested that there was an important connection between the attitude of teachers and the success of students.

Furthermore, Tarik (2000) conducted a study in which he investigated the effect of teacher attitudes on the performance of students. He found out that negative teacher attitudes about science had negative effect on the academic performance of the students.

Moreover, a study conducted by L.Koh, Steers and Terborg (1995) investigated the effect of teacher attitudes on the academic performance. A sample of 89 schools was examined in Singapore using a split sample technique $(N=846$ teachers). The study sought to examine the influence of teacher attitudes on academic performance of students. Attitudinal and behavioral data were collected from both teachers; student academic performance was collected from school records. The analyses showed that teacher attitudes had a significant effect on the academic performance of students. Another study by Soric (2011) examined the effect of teacher 
attitudes on the academic performance of students. The study collected data from 19 teachers. The study adopted internet-based survey and found out a positive correlation between teacher attitudes and academic performance of students.

Most previous academic articles in Somaliland dealt with student related factors, policy analysis factors and education sector analysis. Some also concentrated on teacher characteristics but abandoned the indispensability of teacher attitudes. This leaves us a great gap which yet remains an in-depth problem to our improving education system. Therefore, this paper examines if teacher attitudes affect the academic performance of pupils particularly those undertaking public primary schools in Hargeisa District.

Further, as shown by the Somaliland Certificate of Primary Education, the performance of pupils in primary schools has decreased in the last five years. For students, the number of failures rose by 21 percent from 20142018. In Somaliland, the number of failures was $31 \%$ in 2014 and $30 \%$ in 2015, 40 percent in 2016, 51.2\% in 2017 and 48.4\% in 2018. Between 2014 and 2018, the number of failures increased by 16 percent in Hargeisa. The proportion of failures was $36 \%$ in $2014,38 \%$ in $2015,40 \%$ in $2016,52.2 \%$ in 2017 and $51.97 \%$ in 2018 . On average, in the last five years, the performance of pupils in primary schools in Hargeisa dropped by 16 percent, representing an average percentage loss rise of 3.2 percent each year. The influence of teacher quality on academic performance has not been studied, despite the low performance and worsening of primary school education. Accessible research has not delved into whether or not the quality of teachers influences results. The bad output could continue unchanged without this data, and this could negatively and widely affect the performance of tertiary education.

Therefore, this paper tries to explore if teacher attitudes have any involvement of the declining academic performance of students in public primary schools in Hargeisa District as reflected in National Exams Office (2018).

Consequently, the findings of this research are expected to help the Ministry of Education improve the education system of Somaliland.

\section{METHOD}

The study was conducted in Hargeisa district, Somaliland. This study was conducted through a cross-sectional design. The sample size consisted of 160 teachers.

The research used the process of stratified sampling to pick the sample. It is used when there are separate and mutually exclusive subgroups in the population; this implies that a member does not simultaneously belong to more than one subgroup (Oso, 2016). Since 178 teachers from 21 schools where each teacher can not belong to two schools are involved in this analysis, a proportionate stratified sampling approach was adopted. Within a short period of time, the standardized questionnaire allowed the researcher to gather data on teacher attitudes. The first term examination was included in the records to be reviewed. ANOVA One Way was also used to assess if there were major variations between the means of teacher attitude groups.

\section{RESULTS}

The salient purpose of this study was to investigate effect of teacher attitudes on academic performance of pupils in primary schools in Hargeisa district. Teacher attitudes were operationalized into the model of affective, behavioral and cognitive component. Respondents reacted several items on each variable and the responses were used to determine the attitudes of the teachers in public primary schools.

Table 1

Descriptive Statistics of Teacher Attitudes and Academic Performance

\begin{tabular}{lrrrr}
\hline Teacher Attitudes & $\mathrm{N}$ & Average Performance & $\mathrm{S}$ & $\varepsilon$ \\
\hline Low & 107 & 45.6 & 12.176 & 1.177 \\
Moderate & 45 & 55.36 & 12.946 & 1.930 \\
High & 8 & 83 & .000 & .000 \\
Total & 160 & 50.20 & 14.87 & 1.176 \\
\hline
\end{tabular}

Note. $\mathrm{N}=$ Sample, $\mathrm{S}=$ Standard deviation, $\varepsilon=$ standard error.

Table 11 shows the descriptive statistics of academic performance of pupils in primary schools in Hargeisa district against different teacher attitudes. The table shows that the mean performance of students taught by teachers with high teacher attitudes $(83 \% \mathrm{~S}=.000)$ was higher than the performance of students taught by pupils of teachers with moderate teacher attitudes $(55.3 \%, \mathrm{~S}=12.946)$ and teachers with low subject matter knowledge $(45.6 \%, \mathrm{~S}=12.176)$. The data depicts the factual statement that that academic performance of pupils is affected by the teacher attitude of the teachers. The results showed that teacher attitude affect academic performance of pupils in public primary schools in Hargeisa. Consequently, the higher the attitude of the teachers, the better the academic performance of pupils in public primary schools in Hargeisa district.

Hypothesis states that teacher attitude does not affect the academic performance of pupils in public primary 
schools in Hargeisa.

In the average performance of students taught under teachers with poor, moderate and high teacher attitudes, there is no obvious difference.

$$
\begin{aligned}
& \mathrm{Ho}_{4}: \mathrm{TA}_{\mathrm{L}}=\mathrm{TA}_{\mathrm{M}}=\mathrm{TA}_{\mathrm{H}} \\
& \mathrm{H}_{\mathrm{A} 4:} \mathrm{TA}_{\mathrm{L}} \neq \mathrm{TA}_{\mathrm{M}} \neq \mathrm{TA}_{\mathrm{H}}
\end{aligned}
$$

Where $\mathrm{TA}_{\mathrm{L}}$ is low teacher attitude; $\mathrm{TA}_{\mathrm{M}}$ is moderate teacher attitude and $\mathrm{TA}_{H}$ stands for high teacher attitude.

The results for ANOVA are shown in Table 12.

Table 2

F-Statistics of Performance of Pupils with Subject Matter Knowledge

\begin{tabular}{lccccc}
\hline Source of difference & Sums of Squares & df & Mean square & F & P \\
\hline Between & 12087.214 & 2 & 6043.607 & 41.089 & .000 \\
Within & 23092.386 & 157 & 147.085 & & \\
\hline Total & 35179.600 & 159 & & & \\
\hline
\end{tabular}

Note. $\mathrm{F}(2,157)=3.06$

The ANOVA performance statistics of pupils taught by teachers with poor, moderate, and high attitudes are shown in Table 2. The findings suggest that the performance of pupils taught by teachers with poor, moderate and high attitudes, $\mathrm{Fo}=41.089>\mathrm{F}(2,157)=3.06 ; \mathrm{p}=.000$, is substantially different. This led to the null hypothesis being rejected. It indicates that the output of pupils taught by teachers with poor, moderate and high attitudes is substantially different.

The study, therefore, established that teacher attitude affects academic performance of pupils in public primary schools in Hargeisa district. The higher the teacher attitude, the better the performance of the pupils.

More so, LSD post-hoc yielded a significant difference between the performance of pupils with teachers of low and moderate attitude, $(\mathrm{I}-\mathrm{J}=9.776, P=.000)$ and with teachers of low and high attitude (I-J $=37.421, P$ $=.000)$. There is also a significant difference between moderate and high teacher attitudes $(\mathrm{I}-\mathrm{J}=27.644, P$ $=.000)$. Therefore, teachers with high attitudes $(83 \%, \mathrm{~S}=.000)$ have higher performance than teachers with low teacher attitude $(45.6 \%, \mathrm{~S}=12.176)$. Also, teachers with moderate attitude have higher student performance $(55.3 \%, \mathrm{~S}=12.946)$ than teachers with low attitude $(45.6 \%, \mathrm{~S}=12.176)$.

The eta-square returned an average value of $\eta^{2}=34.4 \%$. Therefore, teacher attitude accounts for $34.4 \%$ of the variance in academic performance of pupils in pubic primary schools in Hargeisa. The rest $65.6 \%$ are due to factors not investigated here, and errors in measurements. Academic performance can be affected by up to $34.4 \% \%$ through manipulation teacher attitudes.

\section{DISCUSSION}

The study unveiled that teacher attitude has a substantial effect on the academic performance of pupils of primary schools in Hargeisa districts, $F o=41.089>\mathrm{F}(2,157)=3.06 ; \mathrm{p}=.000$. This finding can be understood that teachers with high attitudes can improve the performance of pupils - that is, the higher the attitude of the teacher the better to obtain the desired academic performance of pupils in public primary schools. L.Koh, Steers and Terborg (1995) investigated the effect of teacher attitudes on the academic performance. The study found out a positive relationship between teacher attitude and academic performance. Another study by Soric (2011) found out that teachers' attitudes could influence the performance of students. Besides that, Mitchell (1976) stated that the attitudes of the teacher are a positive correlate to the academic performance of students.

The above finding concurs with previous findings. Sutton (2013) investigated the relationship between teacher attitudes and the academic performance of students using ANOVA and PEARSON Correlations. The results of this study suggested that there was a significant relationship between teachers' attitude and student performance. Tarik et al. (2000) conducted a study in which he investigated the effect of teacher attitudes on the performance of students. He found out that negative teacher attitudes about science had negative effect on the academic performance of the students. As a result, this generally reflects as the sentiment that teacher attitudes are linked with academic performance of pupils in primary schools in Hargeisa.

\section{REFERENCES}

Awan, K. H., Hammam, M. K., \&Warnakulasuriya, S. (2015). Knowledge and Attitude of Tobacco use and cessation among dental professionals. The Saudi dental journal, 27(2), 99-104.

Gahayr, A.(2018).Effect of Medium of Instruction on Academic Performance:Alhuseini printer center.Hargeisa Somaliland

Hanushek, E. A., \&Woessmann, L. (2012). Do better schools lead to more growth? Cognitive skills, economic outcomes, and causation.Journal of economic growth, 17(4), 267-321.

Hastings, Richard \& OAKFORD, SUZANNA. (2003). Student Teachers' Attitudes Towards the Inclusion of Children with Special Needs. Educational Psychology, 23(1):87-94.

Joel, J. H.(2012). Attitude Development methods for fluid dynamics. Springer Science .London, England: 
Springer press.

Kingoina, O. J., Kadenyi, M. M., \&Ngaruiya, N. B. (2015). Effect of Teachers' Morale on Standard Eight Pupils' Academic Achievement in Public Primary Schools in Marani Sub-County, Kenya.International Journal of Scientific and Research Publications, 10, 1-9.

Koh, W., Steers,R.\&Terborg, J. (1995). The effects of transformational leadership on teacher attitudes and student performance in Singapore. Journal of Organizational Behavior, 16 (4), 319-333.

Soric, T. (2011). The impact of teacher attitudes on academic achievement in disadvantaged schools. University of Toledo, United States of America.

Cochran-Smith, M. (2005). The new teacher education: For better or for worse?.Educational Researcher, 34(7), 3-17.

Ngina, D. S. (2013). Effects of stress on academic performance among public secondary school teachers in Kathiani District, Kenya.

Oso, W.Y. (2013). Principles and practice of educational research. Borama, Somaliland: Barkhadle Printing Press.

Soric, T. (2011). The impact of teacher attitudes on academic achievement in disadvantaged schools. University of Toledo, United States of America.

Tariq, P. A. (2000). Computer-Based vs Paper-Based Examinations: Perceptions of University Teachers." Turkish Online Journal of Educational Technology-TOJET 11, no. 4 (2012): 371-381. 